\title{
Oxygen-doped carbon host with enhanced bonding and electron attraction abilities for efficient and stable $\mathrm{SnO}_{2} /$ carbon composite battery anode
}

\author{
Zhen Geng ${ }^{1,2}$, Bing Li ${ }^{1}$, Hezhi Liu ${ }^{3}$, Hong Lv $^{1}$, Qiangfeng Xiao ${ }^{4}$, Yongjun $\mathrm{Ji}^{3^{*}}$ and Cunman Zhang ${ }^{1^{*}}$
}

\begin{abstract}
The coupling between electrochemically active material and conductive matrix is vitally important for high efficiency lithium ion batteries (LIBs). By introducing oxygen groups into the nanoporous carbon framework, we accomplish sustainably enhanced electrochemical performance for a $\mathrm{SnO}_{2}$ /carbon LIB. $2-5 \mathrm{~nm} \mathrm{SnO}_{2}$ nanoparticles are hydrothermally grown in different nanoporous carbon frameworks, which are pristine, nitrogen- or oxygen-doped carbons. Compared with pristine and nitrogen-doped carbon hosts, the $\mathrm{SnO}_{2} /$ oxygen-doped activated carbon (OAC) composite exhibits a higher discharge capacity of $1,122 \mathrm{~mA} \mathrm{~h} \mathrm{~g}^{-1}$ at $500 \mathrm{~mA} \mathrm{~g}^{-1}$ after 320 cycles operation and a larger lithium storage capacity up to $680 \mathrm{~mA} \mathrm{~h}^{-1}$ at a high rate of $2,000 \mathrm{~mA} \mathrm{~g}^{-1}$. The exceptional electrochemical performance originated from the oxygen groups, which could act as Lewis acid sites to attract electrons effectively from Sn during the charge process, thus accelerating reversible conversion of Sn to $\mathrm{SnO}_{2}$. Meanwhile, $\mathrm{SnO}_{2}$ nanoparticles are effectively bonded with carbon through such oxygen groups, thus preventing the electrochemical sintering and maintaining the cycling stability of the $\mathrm{SnO}_{2} / \mathrm{OAC}$ composite anode. The high electrochemical performance, low biomass cost, and facile preparation renders the $\mathrm{SnO}_{2} / \mathrm{OAC}$ composites a promising candidate for anode materials.
\end{abstract}

Keywords: tin oxide, nanoporous carbon, functional groups, anode materials, lithium-ion batteries

\section{INTRODUCTION}

As one of the most widely commercialized energy storage devices, lithium-ion batteries (LIBs) have attracted intensive interest during the past decades due to the ad- vantages of light weight, environmental benignity, high energy density and high power density [1]. Although graphite is the dominated anode material for commercial LIBs, its low theoretical capacity ( $\left.372 \mathrm{~mA} \mathrm{~h} \mathrm{~g}^{-1}\right)$ seriously hinders the development of LIBs with higher energy density [2]. Many efforts have devoted to exploring other high-capacity anode materials.

Among many kinds of anode materials, tin oxide $\left(\mathrm{SnO}_{2}\right)$ is regarded as a promising candidate considering its natural abundance, environmental benignity, and high theoretical capacity $\left(782 \mathrm{~mA} \mathrm{~h} \mathrm{~g}^{-1}\right.$ ) [3-6]. However, similar to other anodes with high capacity such as silicon [7-9], large volume change (more than 300\%) during lithiation and delithiation process leads to severe pulverization of electrode, aggregation of $\mathrm{SnO}_{2}$ particles and formation of unstable solid electrolyte interphase (SEI) film, thus resulting in fast capacity fading. So far, two main strategies have been applied to resolve the abovementioned problems. One effective way is to synthesize the nanostructured $\mathrm{SnO}_{2}$, including one dimensional (1D) nanorods/nanotubes/nanowires, 2D nanosheets and $3 \mathrm{D}$ hollow or porous nanostructures [10-13]. The other approach focuses on developing hybrid nanostructure by embedding active $\mathrm{SnO}_{2}$ nanoparticles into conductive carbonaceous matrix such as porous carbon and graphene $[6,14-16]$. It is well demonstrated that the carbon-based hosts play crucial roles as ideal volume change buffers and good electron conductors.

Another drawback of $\mathrm{SnO}_{2}$ based anodes is poor initial Coulombic efficiency (CE) due to the irreversible conversion reaction during the initial electrochemical process, resulting in the insufficient utilization of $\mathrm{SnO}_{2}$ and

\footnotetext{
${ }^{1}$ Clean Energy Automotive Engineering Center, Tongji University, Shanghai 201804, China

${ }^{2}$ Beijing National Laboratory for Condensed Matter Physics, Institute of Physics, Chinese Academy of Sciences, Beijing 100190, China

${ }^{3}$ State Key Laboratory of Multiphase Complex Systems, Institute of Process Engineering, Chinese Academy of Sciences, Beijing 100190, China

${ }^{4}$ General Motors Research and Development Center, Warren, MI 48090, USA

*Corresponding authors (emails: yjji@ipe.ac.cn (Ji Y); zhangcunman@tongji.edu.cn (Zhang C))
} 
additional consumption of cathode materials [17]. The electrochemical processes can be summarized by the equations as follows $[10,11]$ :

$$
\begin{gathered}
\mathrm{SnO}_{2}+4 \mathrm{Li}^{+}+4 \mathrm{e}^{-} \rightarrow \mathrm{Sn}+2 \mathrm{Li}_{2} \mathrm{O}, \\
\mathrm{Sn}+x \mathrm{Li}^{+}+\mathrm{e}^{-} \leftrightarrow \mathrm{Li}_{x} \mathrm{Sn}(0 \leq x \leq 4.4) .
\end{gathered}
$$

In the initial lithiation process, $\mathrm{SnO}_{2}$ is irreversibly converted to Sn (Equation (1)) due to the strong stability of $\mathrm{Li}_{2} \mathrm{O}$, resulting in large capacity loss and low initial CE $(<50 \%)$. Subsequently, reversible alloying/dealloying reaction between $\mathrm{Sn}$ and $\mathrm{Li}$ (Equation (2)) contributes to the dominant capacity. If the conversion reaction of Equation (1) is reversible, the theoretical specific capacity can be increased from 782 (based on $4.4 \mathrm{Li}$ ions) to $1,493 \mathrm{~mA} \mathrm{~h} \mathrm{~g}^{-1}$ (based on $8.4 \mathrm{Li}$ ions), which would significantly improve the capacity of $\mathrm{SnO}_{2}$.

Recently, $\mathrm{SnO}_{2}$ anodes with higher experimental capacity than theoretical capacity were reported in $\mathrm{SnO}_{2} /$ carbon nanocomposites, which was attributed to the synergetic effects benefit from unique hybrid nanostructure [18-23]. However, the detailed mechanism still remains unclear. In another attempt, higher experimental capacity is obtained by ternary composites $\mathrm{SnO}_{2}$ /carbon/ transition metal oxides (e.g., $\mathrm{Co}_{3} \mathrm{O}_{4}, \mathrm{Fe}_{2} \mathrm{O}_{3}$ ), where transition metal oxides nanoparticles can promote the decomposition of $\mathrm{Li}_{2} \mathrm{O}$ and also accelerate reversible conversion of $\mathrm{Sn}$ to $\mathrm{SnO}_{2}$ [24,25]. It is well documented that Lewis acid can promote catalytic oxidation reaction by electron extraction as the electron acceptor, which has been widely used in homogeneous catalysis [26]. Besides, it is reported that tiny size of $\mathrm{Sn}$ nanoparticles $(<5 \mathrm{~nm})$ also could reduce the activation energy for $\mathrm{Li}_{2} \mathrm{O}$ decomposition, thus boosting the partial conversation of $\mathrm{Sn}$ to $\mathrm{SnO}_{2}$ [20]. Therefore, it could be an effective way to achieve reversible oxidation conversion of $\mathrm{Sn}$ to $\mathrm{SnO}_{2}$ by introducing Lewis acid groups into carbon host and combining with tiny size of $\mathrm{SnO}_{2}$ nanoparticles.

Taking these into account, $\mathrm{SnO}_{2} /$ carbon composites are synthesized here by a simple hydrothermal approach, where tiny $\mathrm{SnO}_{2}$ nanoparticles $(2-5 \mathrm{~nm})$ are effectively confined within the nanoporous carbon framework. Besides, Oxygen functional groups are herein introduced into nanoporous carbon matrix as Lewis acid sites in the form of carboxyl, hydroxyl and ester, which can effectively abstract electrons from $\mathrm{Sn}$ during the charge process, thus accelerating reversible conversion from $\mathrm{Sn}$ to $\mathrm{SnO}_{2}$ and resulting in high initial CE. Meanwhile, $\mathrm{SnO}_{2}$ nanoparticles are effectively bonded with carbon through such oxygen groups, thus realizing homogeneous anchor of $\mathrm{SnO}_{2}$ nanoparticles. Besides, nitrogen groups (e.g., pyridinc-N and pyrrolic-N) as Lewis base sites are also introduced into porous carbon as a comparison. The oxygen doped nanocomposites exhibit excellent electrochemical performance, in terms of large specific capacity, high rate capability and long cycling stability.

\section{EXPERIMENTAL SECTION}

\section{Preparation of nanoporous carbon materials}

Original nanoporous carbon was prepared by potassium hydroxide $(\mathrm{KOH})$ chemical activation with biomass corncob as the carbon source and $\mathrm{KOH}$ as the activating agent, according to previous reports $[27,28]$. The pristine carbon sample was hereafter denoted as corncob-derived activated carbon (CAC).

Based on CAC, oxygen doped activated carbon was prepared by nitric acid oxidation. The $\mathrm{CAC}$ was impregnated in concentrated nitric acid at $60^{\circ} \mathrm{C}$ for $2 \mathrm{~h}$ and then washed with adequate deionized water. The dried sample was collected and denoted as OAC.

Based on CAC, nitrogen doped active carbon was prepared by a two-step method. The first step was the above-mentioned nitric acid oxidation; the second step was ammonia $\left(\mathrm{NH}_{3}\right)$ treatment (the OAC sample was placed in a ceramic crucible and then annealed under $\mathrm{NH}_{3}$ atmosphere at $800^{\circ} \mathrm{C}$ for $3 \mathrm{~h}$ ). The final sample was denoted as NAC.

\section{Preparation of $\mathrm{SnO}_{2} /$ carbon composites}

$\mathrm{SnO}_{2} /$ carbon composites were synthesized by a simple hydrothermal approach. Firstly, $0.15 \mathrm{~g}$ carbon was ultrasonically dispersed into $30 \mathrm{~mL}$ stannate aqueous solution $\left(0.15 \mathrm{~g} \mathrm{SnCl}_{2}\right.$ with a purity of $>99.995 \%, 0.3 \mathrm{~mL} \mathrm{HCl}$ (38 wt\%) and $0.3 \mathrm{~g}$ urea, purchased from Sigma-Aldrich). The mixture was stirred for $2 \mathrm{~h}$, then the solution was transferred into $50 \mathrm{~mL}$ Teflon-lined stainless steel autoclave. The solution was subsequently heated to $180^{\circ} \mathrm{C}$ for $12 \mathrm{~h}$ in an oven. After rinsed with large amount of distilled water and ethanol to remove the choloride ions, dried samples were calcined in air at $230^{\circ} \mathrm{C}$ for $5 \mathrm{~h}$. Finally, $\mathrm{SnO}_{2}$ /carbon composites were obtained. According to pore volume of the obtained carbons, $\mathrm{SnO}_{2} /$ carbon composites were prepared with the optimal $\mathrm{SnO}_{2}$ content of $50 \mathrm{wt} \%$, denoted as $\mathrm{SnO}_{2} / \mathrm{CAC}, \mathrm{SnO}_{2} / \mathrm{OAC}$ and $\mathrm{SnO}_{2} /$ NAC respectively.

\section{Materials characterization}

The textural properties of the samples were performed by $\mathrm{N}_{2}$ sorption at $77 \mathrm{~K}$ using a Micromeritics ASAP2020 
Table 1 Textural and chemical characteristic of the as-obtained carbon samples

\begin{tabular}{ccccccc}
\hline Sample & $\begin{array}{c}S_{\text {BET }} \\
\left(\mathrm{m}^{2} \mathrm{~g}^{-1}\right)\end{array}$ & $\begin{array}{c}V_{\mathrm{t}} \\
\left(\mathrm{cm}^{3} \mathrm{~g}^{-1}\right)\end{array}$ & $\mathrm{C}(\mathrm{wt} \%)$ & $\mathrm{N}(\mathrm{wt} \%)$ & $\mathrm{O}(\mathrm{wt} \%)$ & $\mathrm{H}(\mathrm{wt} \%)$ \\
\hline CAC & 2762 & 1.49 & 90.89 & $<0.3$ & 0.01 & 0.76 \\
OAC & 2532 & 1.21 & 77.56 & 0.6 & 6.11 & 4.74 \\
NAC & 2724 & 1.46 & 88.02 & 1.39 & 1.13 \\
\hline
\end{tabular}

$S_{\mathrm{BET}}$, specific surface area calculated by BET equation at $P / P_{0}=0.02-0.25$, correlation coefficient of BET curves for all samples is more than 0.9999 ; $V_{\mathrm{t}}$, total pore volume estimated from the adsorption amount of $\mathrm{N}_{2}$ at $P / P_{0}=0.98$.

over a wide relative pressure ranging from about $10^{-6}$ to 1.0. The surface area was calculated using the BrunauerEmmett-Teller (BET) equation based on adsorption data in the partial pressure $\left(P / P_{0}\right)$ ranging from 0.02 to 0.25 and the total pore volume was determined from the amount of nitrogen adsorbed at a relative pressure of 0.98. Pore size distributions (PSDs) were calculated by using the Density Functional Theory (DFT) Plus Software (provided by Micromeritics Instrument Corporation), which was based on the calculated adsorption isotherms for pores of different sizes. All samples were degassed at $300^{\circ} \mathrm{C}$ for $600 \mathrm{~min}$ prior to the measurements.

The scanning electron microscopy (SEM, FEI SIRION 200/INCA, OXFORD) and transmission electron microscopy (TEM, JEM-2100F, JEOL) were used to determine the morphologies and texture of the samples. The crystal structure of $\mathrm{SnO}_{2}$ /carbon composites was characterized by X-ray diffraction measurement (XRD, Rigaku DLMAX-2200). Elemental analysis (Elementar, vario ELIII) and X-ray photoelectron spectroscopy (XPS, UlVAC-PHI PHI 5000 Versa Probe) were employed to determine the element contents and surface functional groups. Thermogravimetric analysis (TGA) of all $\mathrm{SnO}_{2} /$ carbon composites was carried out with a thermogravimetric analysis instrument (TGA, STA 409 PC Luxx, Germany) under air atmosphere. A high accuracy balance (METTLER TOLEDO with $0.00001 \mathrm{~g}$ accuracy) was used to diminish the experimental error.

\section{Cell fabrication and electrochemical measurement}

The electrochemical performance of the composite electrode was measured using coin-type cells assembled in an argon-filled glove box. The working electrodes were prepared by pasting slurries onto $\mathrm{Cu}$ foil current collector, and dried at $90^{\circ} \mathrm{C}$ for $24 \mathrm{~h}$ under vacuum before testing. The slurry was made by mixing active material ( $\mathrm{SnO}_{2}$ /carbon composites), conductive materials (Super $\mathrm{P}$ carbon black) and binder (poly-vinyldifluoride, PVDF) in a weight ratio of 80:10:10 in $N$-methyl-2-pyrrolidone (NMP). The mass loading of active materials for all pre- pared electrodes was $\sim 2 \mathrm{mg}$ composites per $\mathrm{cm}^{2}$. The specific capacity calculated here was based on the mass of $\mathrm{SnO}_{2} /$ carbon composites. The electrolyte was $1 \mathrm{~mol} \mathrm{~L}^{-1}$ $\mathrm{LiPF}_{6}$ dissolved in a mixture of ethylene carbonate (EC) and dimethyl carbonate (DMC) (1:1 vol/vol) and the separator was glass fiber from Whatman. Lithium foil is used as the counter electrode.

Galvanostatic cycling tests of assembled cells were carried out on a Land CT2001A system (Wuhan Jinnuo Electronics, Ltd., Wuhan, China) in the potential range of 0.01-3 V (vs. $\left.\mathrm{Li}^{+} / \mathrm{Li}\right)$. The cyclic voltammetry (CV) measurements were carried out on a Solartron 1860/1287 Electrochemical Interface (Solartron Analytical, Oak Ridge, $\mathrm{TN}$ ) in the potential range of $0.01-3.0 \mathrm{~V}$ at a scan of $0.2 \mathrm{mV} \mathrm{s}^{-1}$ (vs. $\left.\mathrm{Li}^{+} / \mathrm{Li}\right)$. All the electrochemical tests were conducted at room temperature $\left(25^{\circ} \mathrm{C}\right)$.

\section{RESULTS AND DISCUSSION}

As shown in Table 1, large amounts of functional groups leave from CAC due to severe activation at high temperature, and just a few oxygen groups remain (Fig. 1a). Based on CAC, large amounts of oxygen groups are doped into carbon host by nitric acid oxidation (sample OAC). It is well documented that nitric acid treatment produces mainly oxygen groups into carbon, which improves surface chemical property of carbon matrix [29]. Table 1 shows oxygen content of carbon host significantly increases from $8 \mathrm{wt} \%$ (CAC) to $20.45 \mathrm{wt} \%$ (OAC), which mainly exits as Lewis acid groups (e.g., carboxyl, hydroxyl and ester) (Fig. 1b).

According to previous studies, oxygen groups in biomass play crucial roles on nitrogen doping using $\mathrm{NH}_{3}$ as nitrogen source [30]. Treating CAC with $\mathrm{NH}_{3}$ would lead to reduced nitrogen content $(<2 \mathrm{wt} \%)$ because of the elimination of oxygen groups during $\mathrm{KOH}$ activation. Based on above, the modified nitrogen doping method with two-step was developed, i.e., large amounts of oxygen groups were firstly doped into CAC by nitric acid oxidation, then nitrogen doping was further carried out by $\mathrm{NH}_{3}$ treatment, thus obtaining NAC with high nitro- 

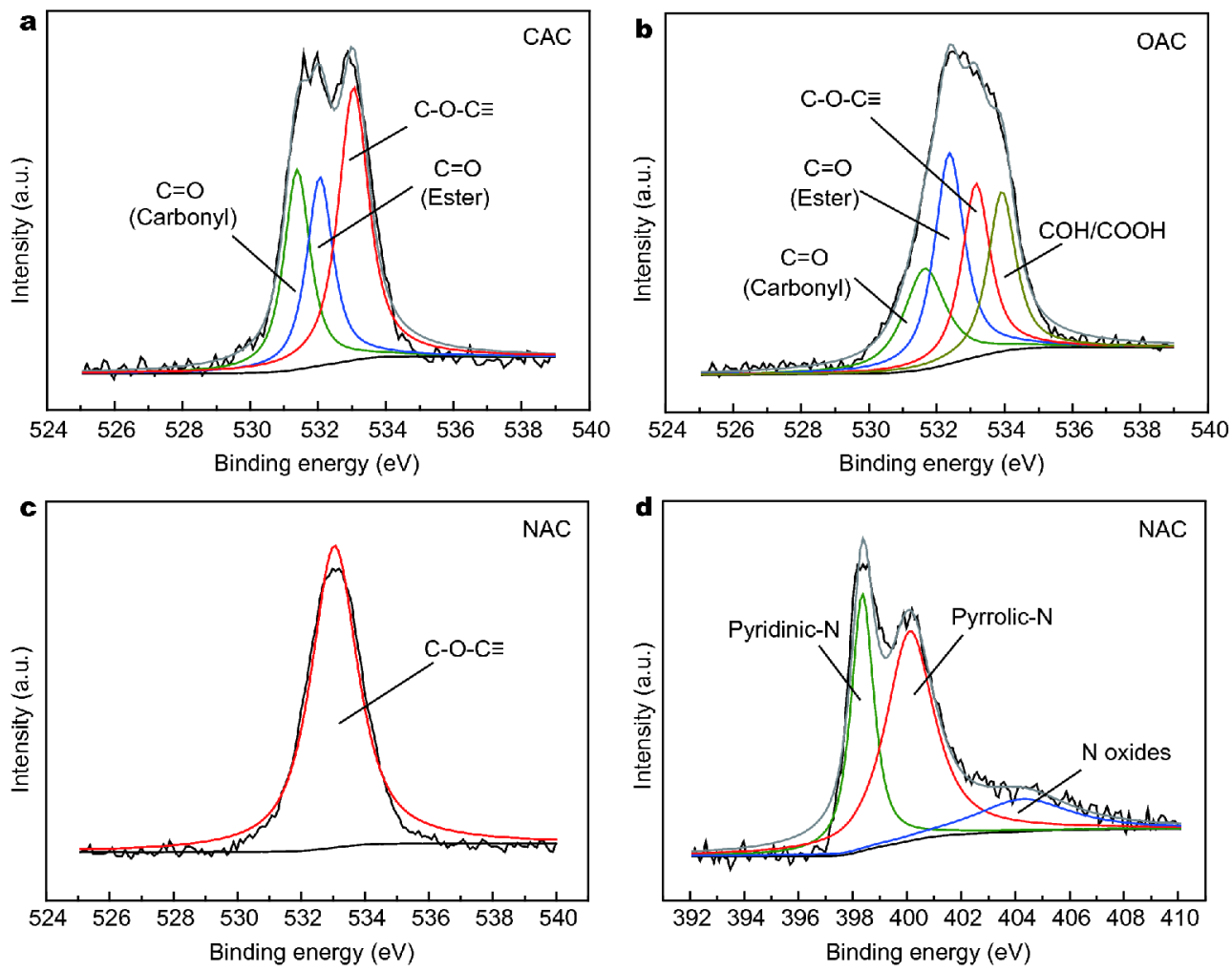

Figure $1 \mathrm{O}$ 1s XPS spectra of (a) CAC, (b) OAC and (c) NAC; (d) N 1s XPS spectra of NAC.

gen content. It provides a highly effective method to prepare nitrogen doped carbons based on existing porous carbons. XPS characterization shows the Lewis base groups mainly present in the form of pyridinic- $\mathrm{N}$ and pyrrolic-N (Fig. 1d). Meanwhile, large amounts of oxygen groups are consumed and finally only $\mathrm{C}-\mathrm{O}$ group remains with the content of $4.74 \mathrm{wt} \%$ (Fig. 1c).

As shown in Fig. 2a, nitric acid oxidation destroys nanoporous structure of $\mathrm{CAC}$, resulting in the slight decrease of surface area of OAC $\left(2,532 \mathrm{~m}^{2} \mathrm{~g}^{-1}\right.$, Table 1). $\mathrm{NH}_{3}$ plays dual roles of activating agent and nitrogen source during the further treatment of OAC with $\mathrm{NH}_{3}$ [30], thus leading to the increase of surface area of NAC. As shown in Fig. 2b, the PSDs of OAC and NAC are similar than that of CAC, ranging from 0.5 to $4 \mathrm{~nm}$. Based on above, a series of ACs with similar surface area and pore structure but different surface chemical properties are fabricated, i.e., acidic for OAC, neutral for CAC and basic for NAC based on Lewis acid-base theory.

As shown in Fig. S1 (see Supplementary information), there are large amounts of irregular granules in CAC, due to irregular characteristic of corncob powders. In Fig. 3a, numerous slit-shaped nanopores are formed in CAC, which is the characteristic of amorphous carbon. As shown in Fig. 3b, the morphology of representative sample $\mathrm{SnO}_{2} / \mathrm{CAC}$ composite is unchanged, compared with the original CAC sample (Fig. S1), which indicates most of $\mathrm{SnO}_{2}$ nanoparticles are restricted to grow within the carbon host. In Fig. 3c, element mapping shows $\mathrm{SnO}_{2}$ is homogenously distributed in the carbon framework, which is beneficial for alleviating aggregation of $\mathrm{SnO}_{2}$ nanoparticles and pulverization of electrode during the lithiation and delithiation process. At the same time, conductive nanoporous structure can facilitate the penetration of electrolyte into the hybrid nanostructure to enhance Li ions accessibility. As shown in Fig. 3d, $\mathrm{SnO}_{2}$ nanoparticles with the diameter ranging from 2 to $5 \mathrm{~nm}$ are uniformly dispersed on CAC. It is worth noting that so tiny $\mathrm{SnO}_{2}$ nanoparticles could reduce the activation energy for $\mathrm{Li}_{2} \mathrm{O}$ decomposition reaction and boost the partial conversation of $\mathrm{Sn}$ to $\mathrm{SnO}_{2}$ during the charge process [20]. The interplanar spaces of the nanoparticles are measured to be $0.33,0.26$ and $0.17 \mathrm{~nm}$, corresponding to the (110), (102) and (211) crystal planes of tetragonal rutile $\mathrm{SnO}_{2}$, respectively (Fig. 3e) [20,25]. Besides, layer nanostructure of graphite is also detected at the edge of 

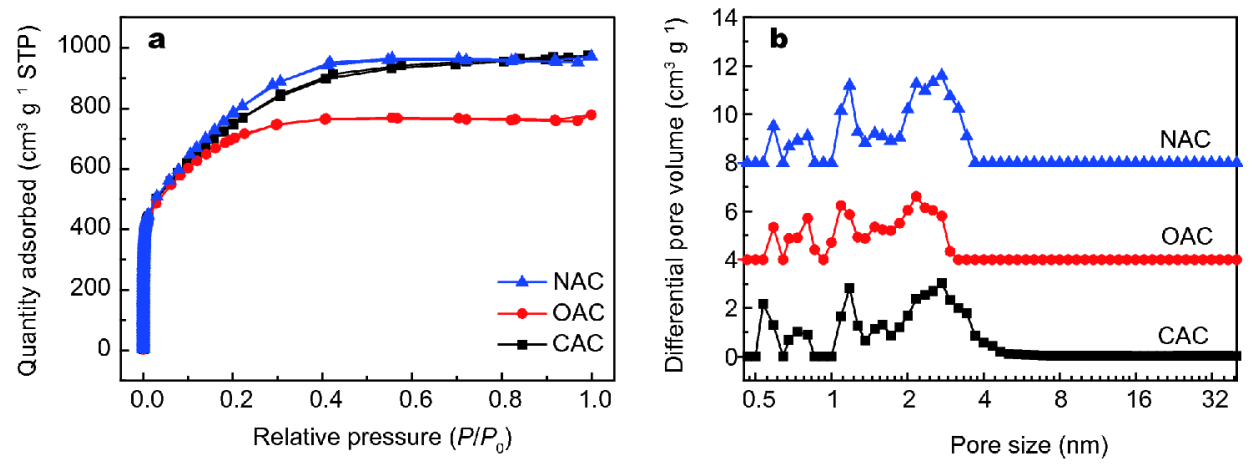

Figure 2 (a) $\mathrm{N}_{2}$-sorption isotherms and (b) pore size distributions of all the as-obtained samples.
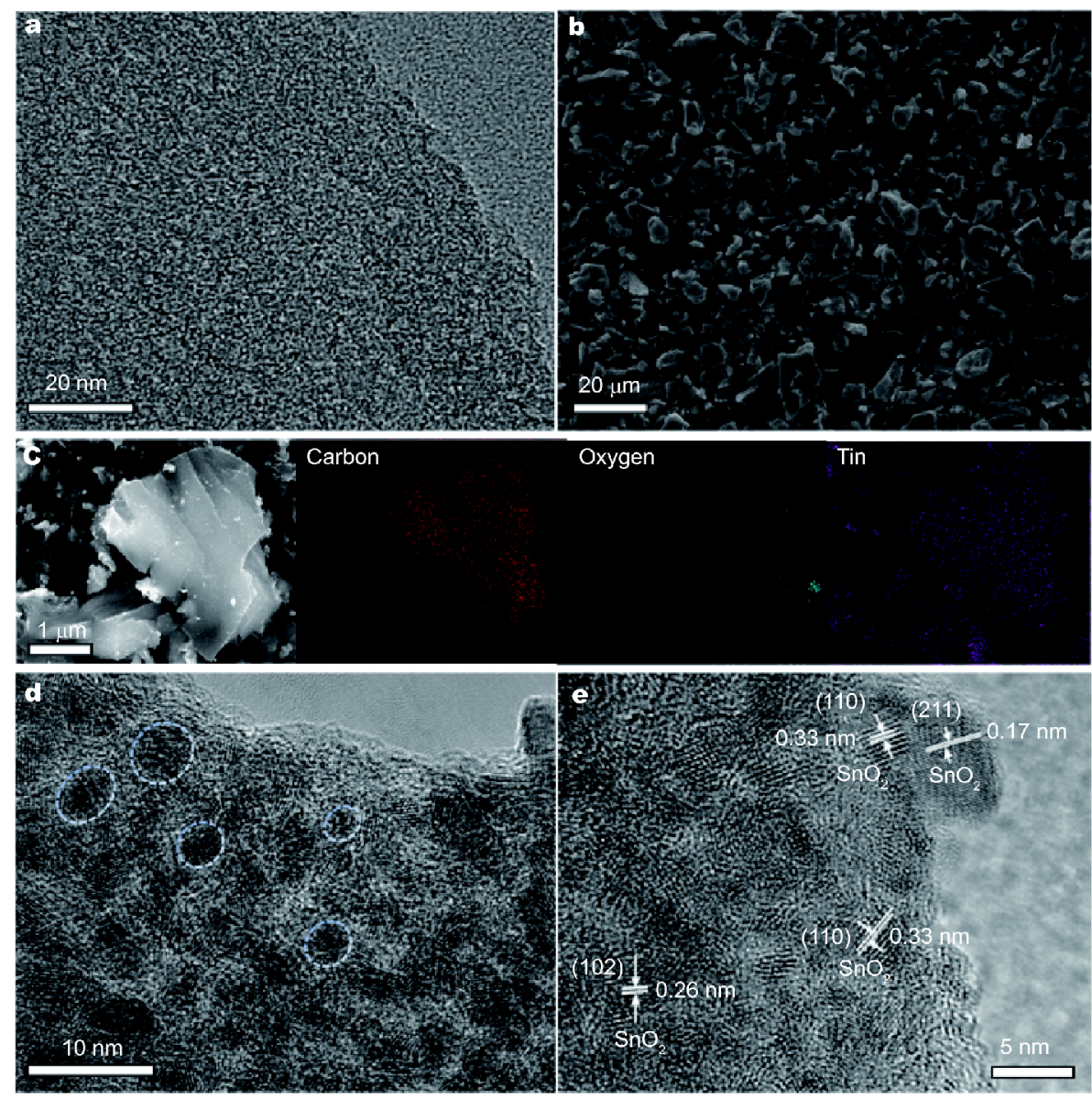

Figure 3 (a) TEM image of CAC; (b) SEM image of $\mathrm{SnO}_{2} / \mathrm{CAC}$; (c) element mapping of $\mathrm{SnO}_{2} / \mathrm{CAC}$; (d) and (e) HRTEM image of $\mathrm{SnO}_{2} / \mathrm{CAC}$.

carbon host due to the carbon atom restructuring caused by $\mathrm{KOH}$ activation, which is beneficial for conductivity improvement of carbon host.

The crystal structure of nanocomposites is examined by XRD patterns, as shown in Fig. 4a. It can be seen that
XRD patterns of three composites are quite similar. All intensive peaks match well with rutile $\mathrm{SnO}_{2}$ (JCPDS No. 41-1445), illustrating that $\mathrm{SnCl}_{2}$ is completely transformed to well-crystallized $\mathrm{SnO}_{2}$. Based on the Scherrer equation, the particle sizes of $\mathrm{SnO}_{2} / \mathrm{CAC}, \mathrm{SnO}_{2} / \mathrm{OAC}$ and 

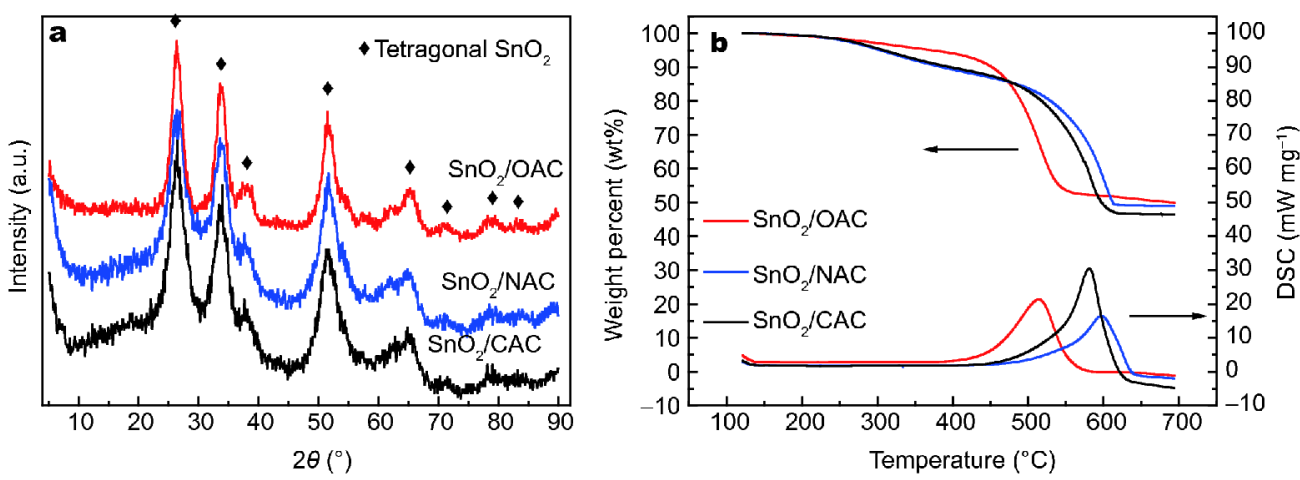

Figure 4 (a) XRD patterns and (b) TGA curves of all the as-obtained samples.

$\mathrm{SnO}_{2} / \mathrm{NAC}$ are calculated to be $5.23,4.91$, and $4.53 \mathrm{~nm}$, respectively, consistent with the TEM observation (Fig. 3d, Figs S2 and S3). It indicates that different surface chemical property for carbon hosts has no obvious effects on the distribution and size of $\mathrm{SnO}_{2}$ nanoparticles.

The accurate content of $\mathrm{SnO}_{2}$ in composites is measured by thermal gravimetric analyses (TGA) conducted in air. As shown in Fig. 4b, three composites contain the similar $\mathrm{SnO}_{2}$ content, i.e., $47 \mathrm{wt} \%$ for CAC, $50 \mathrm{wt} \%$ for OAC and $49 \mathrm{wt} \%$ for NAC. Weight loss process represents the combustion process of carbon host in air. Exothermic peak has a shift to some extent, which is mainly attributed to different oxygen content of three composites (i.e. $20.45 \mathrm{wt} \%$ for OAC, $8.01 \mathrm{wt} \%$ for CAC, $4.74 \mathrm{wt} \%$ for NAC in Table 1). Oxygen groups play a role of combustion-supporting agent in combustion engineering [31]. Thus, combustion is more sufficient with increasing oxygen content, resulting in exothermic peak shifts to lower temperature.

Interaction between $\mathrm{SnO}_{2}$ nanoparticles and functional groups results in totally different electrochemical performance of $\mathrm{SnO}_{2} /$ carbon composites. Among them, $\mathrm{SnO}_{2} / \mathrm{OAC}$ presents the obviously enhanced performance. Charge-discharge curves during the first $150 \mathrm{cy}-$ cles of $\mathrm{SnO}_{2} / \mathrm{OAC}$ at a current density of $500 \mathrm{~mA} \mathrm{~g}^{-1}$ (activated at the first 3 cycles using $200 \mathrm{~mA} \mathrm{~g}^{-1}$ ) are shown in Fig. 5a. The $\mathrm{SnO}_{2} / \mathrm{OAC}$ electrode delivers the discharge and charge capacity of 1,745 and $1,183 \mathrm{mAh} \mathrm{g}^{-1}$ for the first cycle, respectively. It is worth mentioning that the initial $\mathrm{CE}$ of $\mathrm{SnO}_{2} / \mathrm{OAC}$ is $67.8 \%$, which is higher than that of $\mathrm{SnO}_{2} / \mathrm{CAC}(60.4 \%)$ and $\mathrm{SnO}_{2} / \mathrm{NAC}(57.9 \%)$ electrodes, as shown in Figs S4 and S5, respectively. According to initial electrochemical process (Equations (1) and (2)), totally 8.4 mole Li-ions are utilized during the first lithiation process if one mole of $\mathrm{SnO}_{2}$ involves in the reaction. However, due to irreversibility of the reaction in
Equation (1), at least 4 mole Li-ions are inactivated in the following delithiation process, leading to a low initial CE ( 52\%). Higher initial CE of $\mathrm{SnO}_{2} / \mathrm{OAC}$ implies probable partial reversible conversion from $\mathrm{Sn}$ to $\mathrm{SnO}_{2}$. The $32.2 \%$ capacity loss is generally attributed to irreversible formation of the SEI layer on the surface of the nanocomposites and partial irreversible conversion of $\mathrm{Sn}$ to $\mathrm{SnO}_{2}[11,20,25]$. The $\mathrm{CE}$ is further increased to almost $100 \%$ for subsequent cycles (Fig. 5e), indicating the excellent reversibility of the electrode.

Fig. 5b shows CV curves of the first four cycles of $\mathrm{SnO}_{2} /$ OAC electrode within the potential range of $0.01-3 \mathrm{~V}$ at a scanning rate of $0.2 \mathrm{mV} \mathrm{s}^{-1}$. In the first cathodic cycle, a cascade of reduction wave is observed, corresponding to (from higher to lower potential) the reduction of $\mathrm{SnO}_{2}$ to $\mathrm{Sn}$, the formation of SEI film, and alloying reaction of $\mathrm{Sn}$ with $\mathrm{Li}$ to form $\mathrm{Li}_{x} \mathrm{Sn}$ alloy [32]. In the first anodic cycle, the peak at $0.5 \mathrm{~V}$ responds to the dealloying process to form $\mathrm{Sn}$, and the peaks at 1.3 and $2.5 \mathrm{~V}$ could be assigned to the partial conversion reaction of $\mathrm{Sn}$ to $\mathrm{SnO}_{2}$ accompanied with the decomposition of $\mathrm{Li}_{2} \mathrm{O}$ [25]. The subsequent $\mathrm{CV}$ curves are almost identical, indicating reversible and stable electrochemical performance of $\mathrm{SnO}_{2} / \mathrm{OAC}$ composite.

Fig. $5 \mathrm{c}$ shows the galvanostatic cycling performances of $\mathrm{SnO}_{2} /$ carbon composites. It is found that at the same current density ( $\left.500 \mathrm{~mA} \mathrm{~g}^{-1}\right), \mathrm{SnO}_{2} / \mathrm{OAC}$ exhibits the best cycling stability with a high discharge capacity of $930 \mathrm{~mA} \mathrm{~h} \mathrm{~g}^{-1}$ at $150^{\text {th }}$ cycle, suggesting high reversibility and utilization of $\mathrm{SnO}_{2}$. After stabilizing for 60 cycles, $\mathrm{SnO}_{2} / \mathrm{CAC}$ shows a fast capacity fading. Among them, $\mathrm{SnO}_{2} / \mathrm{NAC}$ shows the worst cycling performance, presenting a serve capacity fading. In addition, as shown in Fig. 5 d, $\mathrm{SnO}_{2} / \mathrm{OAC}$ composite also displays an excellent rate performance at a current density from 100 to $2,000 \mathrm{~mA} \mathrm{~g}^{-1}$, superior to $\mathrm{SnO}_{2} / \mathrm{CAC}$ and $\mathrm{SnO}_{2} / \mathrm{NAC}$. 

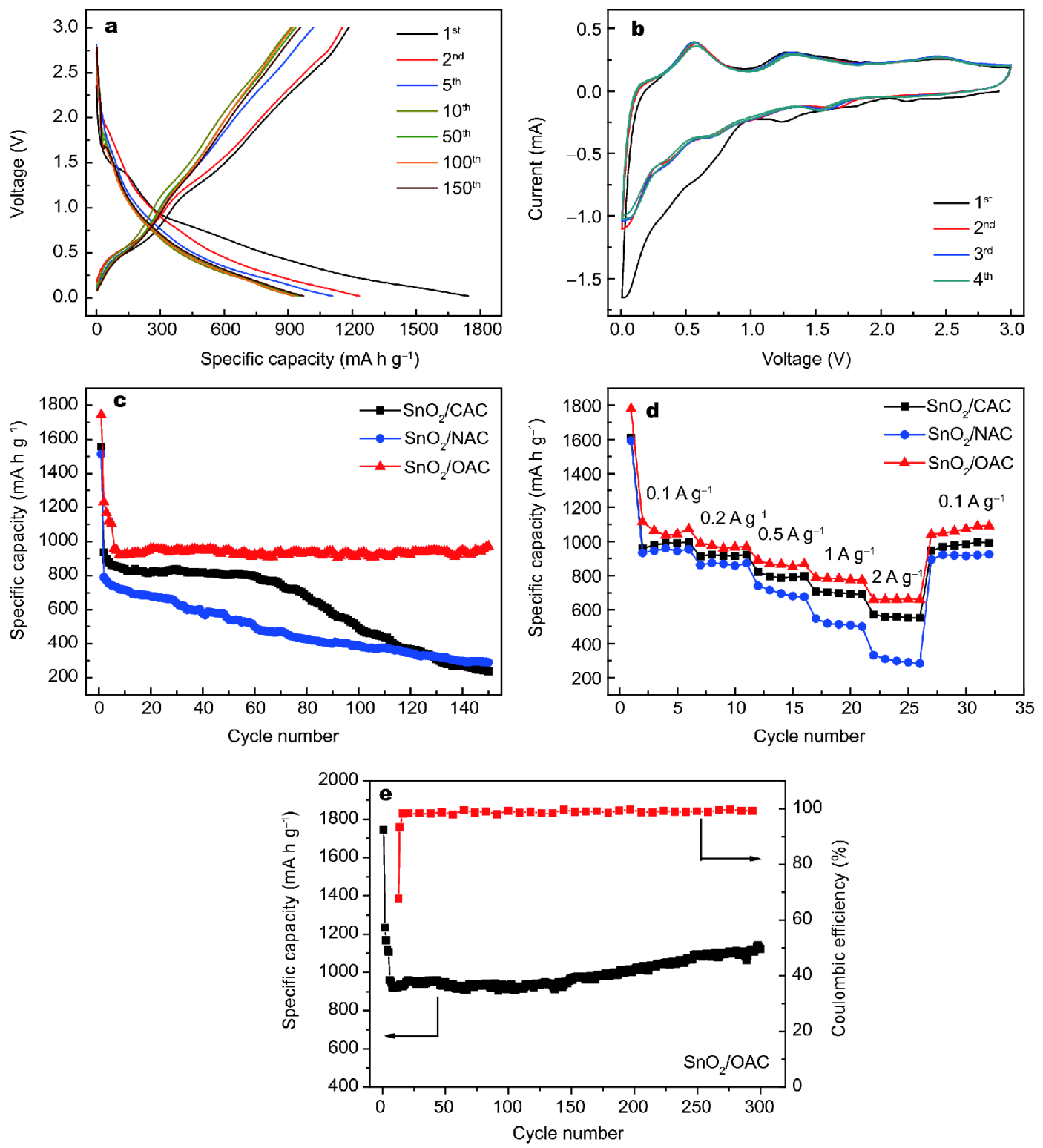

Figure 5 (a) Discharge-charge profiles of $\mathrm{SnO}_{2} / \mathrm{OAC}$ for 150 cycles; (b) $\mathrm{CV}$ curves of $\mathrm{SnO}_{2} / \mathrm{OAC}$ at a scanning rate of $0.2 \mathrm{mV} \mathrm{s}$ for 4 cycles; (c) cycling performance of all samples at $500 \mathrm{~mA} \mathrm{~g}^{-1}$; (d) rate performance of all samples; (e) long cycling performance and Coulombic efficiency of $\mathrm{SnO}_{2} /$ $\mathrm{OAC}$ at $500 \mathrm{~mA} \mathrm{~g}^{-1}$.

Remarkably, a high lithium storage capability of $680 \mathrm{~mA} \mathrm{~h} \mathrm{~g}^{-1}$ at a high rate of $2,000 \mathrm{~mA} \mathrm{~g}^{-1}$ can still be obtained for the $\mathrm{SnO}_{2} / \mathrm{OAC}$ composite. Moreover, the specific capacity can be restored to around $1,100 \mathrm{~mA} \mathrm{~h} \mathrm{~g}^{-1}$ when the current rate is reversed back to $100 \mathrm{~mA} \mathrm{~g}^{-1}$. More interestingly, starting from the $150^{\text {th }}$ cycle, the discharge capacity of $\mathrm{SnO}_{2} / \mathrm{OAC}$ increases gradually to $1,122 \mathrm{mAh} \mathrm{g}^{-1}$ for 320 cycles, as shown in Fig. 5e. The increasing capacity could be explained by gradually reversible conversion of $\mathrm{Sn}$ to $\mathrm{SnO}_{2}$, extra in- terfacial charge storage between $\mathrm{SnO}_{2}$ and carbon, as well as the reversible formation of a polymeric layer at the electrode-electrolyte interface [21-23].

To the best of our knowledge, the electrochemical performance of the $\mathrm{SnO}_{2} / \mathrm{OAC}$ is one of the best of the reported $\mathrm{SnO}_{2}$ based anode materials, in terms of large specific capacity, high rate performance and long cycling stability $[10-12,14-17,24]$. Besides, other advantages, e.g., low biomass cost and facile preparation method, also make $\mathrm{SnO}_{2} / \mathrm{OAC}$ composites become an ideal candidate 

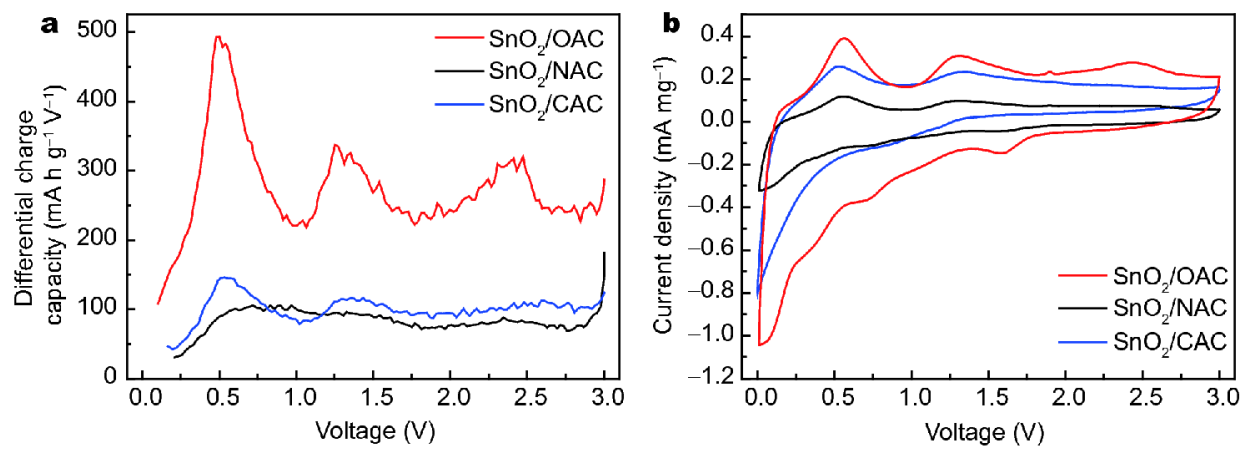

Figure 6 (a) Differential charge capacity versus voltage plots of all samples for $150^{\text {th }}$ cycle at $500 \mathrm{~mA} \mathrm{~g}^{-1}$; (b) CV curves of all samples at a scanning rate of $0.2 \mathrm{mV} \mathrm{s}^{-1}$ for $2^{\text {nd }}$ cycle.

for anode materials in applications.

Obvious performance differences among three samples indicate that functional groups play crucial roles in the electrochemical performance of $\mathrm{SnO}_{2} /$ carbon composites, considering the similar $\mathrm{SnO}_{2}$ content, size and distribution of nanoparticles and surface area of carbon host. Ocontaining groups play a positive role, opposite to Ncontaining groups. The excellent electrochemical performance of $\mathrm{SnO}_{2} / \mathrm{OAC}$ can be attributed to several possible reasons: (1) microporous carbon host effectively buffers the volume changes of $\mathrm{SnO}_{2}$ nanoparticles during the lithiation and delithation process; (2) carbon host prevents the aggregation of $\mathrm{SnO}_{2}$ nanoparticles during cycling; (3) $\mathrm{SnO}_{2}$ nanoparticles are bonded with carbon through oxygen groups such as carbonyl and carboxylic groups, thus realizing homogeneous anchor of $\mathrm{SnO}_{2}$ nanoparticles [20]; and (4) reversible conversion of Sn to $\mathrm{SnO}_{2}$ during the delithiation process. It is easy to understand the first three reasons for the improved cycling performance and rate capability. However, reversible conversion of $\mathrm{Sn}$ to $\mathrm{SnO}_{2}$ is still controversial. Although it is commonly believed that the conversion of $\mathrm{Sn}$ to $\mathrm{SnO}_{2}$ is an irreversible reaction during delithiation process, there are some reports which attempt to probe the presence of partial conversion $[19,20,25]$. It is reported that the required activation energy for conversion of $\mathrm{Sn}$ to $\mathrm{SnO}_{2}$ and $\mathrm{Li}_{2} \mathrm{O}$ decomposition reactions would be reduced with the decrease of nanoparticle size [20]. In this case, $\mathrm{SnO}_{2}$ nanoparticles for sample $\mathrm{SnO}_{2} / \mathrm{OAC}$ and $\mathrm{SnO}_{2} / \mathrm{NAC}$ (i.e., $2-5 \mathrm{~nm}$ ) are small enough to promote reversible conversion of $\mathrm{Sn}$ to $\mathrm{SnO}_{2}$, as previously reported by other groups. However, $\mathrm{SnO}_{2} / \mathrm{NAC}$ shows so weak electrochemical performance, even weaker than pure $\mathrm{SnO}_{2}$ powders [11], implying functional groups play crucial roles on the electrochemical performance of $\mathrm{SnO}_{2} /$ carbon composites. Nitrogen groups play a negative role, oppo- site to oxygen groups, which could be attributed to effects of Lewis acid and base groups on electrons during the lithiation and delithiation process.

Oxygen groups are doped into CAC as Lewis acid groups, which is the electron acceptor during the electrochemical process. It is well documented that Lewis acid can promote catalytic oxidation reaction by electron abstraction as the electron acceptor, which has been widely used in homogeneous catalysis [26]. It can abstract electrons from Sn during the charge process combining with tiny $\mathrm{SnO}_{2}$ nanoparticles, thus making the conversion from $\mathrm{Sn}$ to $\mathrm{SnO}_{2}$ available and leading to the higher initial $\mathrm{CE}$ of $\mathrm{SnO}_{2} / \mathrm{OAC}$, compared with $\mathrm{SnO}_{2} / \mathrm{CAC}$ and $\mathrm{SnO}_{2} /$ NAC. Fig. 6a shows differential charge capacity versus voltage plots of three samples after 150 cycles. Compared with $\mathrm{SnO}_{2} / \mathrm{CAC}$ and $\mathrm{SnO}_{2} / \mathrm{NAC}$, peaks at 1.3 and $2.5 \mathrm{~V}$ for $\mathrm{SnO}_{2} / \mathrm{OAC}$ demonstrate reversible conversion of $\mathrm{Sn}$ to $\mathrm{SnO}_{2}$ by incorporating Lewis acid sites into carbon host, which is also demonstrated by CV curves at the $2^{\text {nd }}$ cycle (Fig. 6b). At the same time, the strong interaction between $\mathrm{SnO}_{2}$ and oxygen groups prevents the electrochemical sintering of $\mathrm{SnO}_{2}$ nanoparticles [33-35]. Thus, high capacity can be kept at the high rate (Fig. $5 \mathrm{~d}$ ).

Fig. 7a shows TEM image of $\mathrm{SnO}_{2} / \mathrm{OAC}$ after cycling, where uniform tiny $\mathrm{SnO}_{2}$ nanoparticles $(\sim 2 \mathrm{~nm})$ still maintain the homogeneous distribution due to the strong interaction between $\mathrm{SnO}_{2}$ and oxygen groups. Compared with oxygen groups, nitrogen groups are doped into carbon in the form of pyridinc-N and pyrrolic-N, considered as Lewis base groups. Opposite to oxygen groups, nitrogen groups as the electron provider make the conversion of $\mathrm{Sn}$ to $\mathrm{SnO}_{2}$ harder, which could have repelled the interactions between $\mathrm{Sn}$ and nitrogen groups. Thus, $\mathrm{Sn}$ nanoparticles is easier to aggregate during the electrochemical process, which makes the capacity of $\mathrm{SnO}_{2} /$ NAC severely degrade, as demonstrated by TEM image of 


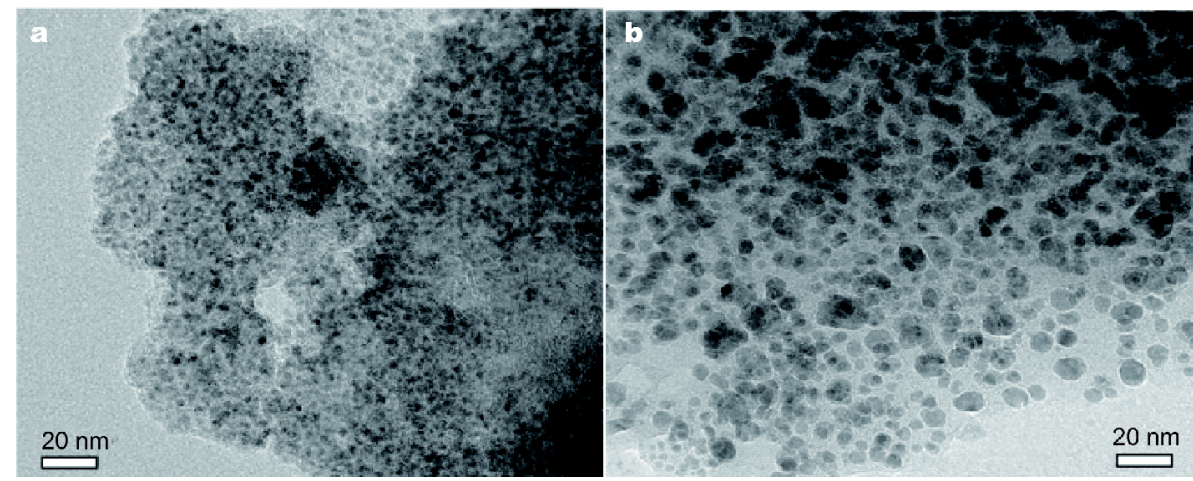

Figure 7 HRTEM images of sample (a) $\mathrm{SnO}_{2} / \mathrm{OAC}$ and (b) $\mathrm{SnO}_{2} / \mathrm{NAC}$ charged to $3 \mathrm{~V}$ at $500 \mathrm{~mA} \mathrm{~g}^{-1}$ after 150 cycles.

$\mathrm{SnO}_{2} / \mathrm{NAC}$ after cycling (Fig. 7b). As shown in Fig. 7b, most of original $\mathrm{SnO}_{2}$ nanoparticles $(2-5 \mathrm{~nm})$ are aggregated into big nanoparticles $(5-10 \mathrm{~nm})$ on the outer surface of carbon.

\section{CONCLUSIONS}

In summary, $\mathrm{SnO}_{2} /$ carbon composites were synthesized here by a simple hydrothermal approach, where tiny $\mathrm{SnO}_{2}$ nanoparticles $(2-5 \mathrm{~nm})$ were effectively refined within the nanoporous carbon framework. Different kinds of functional groups were doped into carbon hosts to study the influence of surface chemical property of carbon host on the electrochemical performance of $\mathrm{SnO}_{2} /$ carbon composites anode. It indicates oxygen groups as Lewis acid sites effectively abstract electrons from Sn during the charge process, thus accelerating reversible conversion of $\mathrm{Sn}$ to $\mathrm{SnO}_{2}$ and resulting in high initial Coulombic efficiency. Meanwhile, $\mathrm{SnO}_{2}$ nanoparticles are effectively bonded with carbon through such oxygen groups, thus realizing homogeneous anchor of $\mathrm{SnO}_{2}$ nanoparticles. The resulting $\mathrm{SnO}_{2} / \mathrm{OAC}$ exhibits excellent electrochemical performance. The performance of the $\mathrm{SnO}_{2} /$ OAC is one of the best $\mathrm{SnO}_{2}$ based anode materials, in terms of large specific capacity, high rate performance and long cycle stability. Besides, other advantages, e.g., low biomass cost, facile preparation method, also make $\mathrm{SnO}_{2} / \mathrm{OAC}$ composites become an ideal candidate for anode materials. This work provides a new route about reversible conversion of $\mathrm{Sn}$ to $\mathrm{SnO}_{2}$ by catalytic oxidation of Lewis acid groups. We believe it could be easily extended to other similar metal oxides anode materials, which is very meaningful for improving performance of anodes in LiBs.

Received 18 November 2017; accepted 25 January 2018; published online 10 February 2018
1 Zhang $\mathrm{K}, \mathrm{Hu} \mathrm{Z}$, Tao Z, et al. Inorganic \& organic materials for rechargeable Li batteries with multi-electron reaction. Sci China Mater, 2014, 57: 42-58

2 Zheng H, Jiang K, Abe T, et al. Electrochemical intercalation of lithium into a natural graphite anode in quaternary ammoniumbased ionic liquid electrolytes. Carbon, 2006, 44: 203-210

3 Tarascon JM, Poizot P, Laruelle S, et al. Nano-sized transitionmetal oxides as negative-electrode materials for lithium-ion batteries.. Nature, 2000, 407: 496-499

4 Tarascon JM, Armand M. Issues and challenges facing rechargeable lithium batteries. Nature, 2001, 414: 359-367

5 Aricò AS, Bruce P, Scrosati B, et al. Nanostructured materials for advanced energy conversion and storage devices. Nat Mater, 2005, 4: $366-377$

6 Kim H, Kim SW, Park YU, et al. $\mathrm{SnO}_{2}$ /graphene composite with high lithium storage capability for lithium rechargeable batteries. Nano Res, 2010, 3: 813-821

7 Chan CK, Peng H, Liu G, et al. High-performance lithium battery anodes using silicon nanowires. Nat Nanotech, 2008, 3: 31-35

8 Li W, Zeng L, Wu Y, et al. Nanostructured electrode materials for lithium-ion and sodium-ion batteries via electrospinning. Sci China Mater, 2016, 59: 287-321

9 Ryu J, Hong D, Lee HW, et al. Practical considerations of Si-based anodes for lithium-ion battery applications. Nano Res, 2017, 10: 3970-4002

10 Lou XW, Li CM, Archer LA. Designed synthesis of coaxial $\mathrm{SnO}_{2} @$ carbon hollow nanospheres for highly reversible lithium storage. Adv Mater, 2009, 21: 2536-2539

11 Chen JS, Lou XWD. $\mathrm{SnO}_{2}$-based nanomaterials: synthesis and application in lithium-ion batteries. Small, 2013, 9: 1877-1893

12 Zhang L, Wu HB, Liu B, et al. Formation of porous $\mathrm{SnO}_{2}$ microboxes via selective leaching for highly reversible lithium storage. Energy Environ Sci, 2014, 7: 1013

13 Sun Z, Liao T, Kou L. Strategies for designing metal oxide nanostructures. Sci China Mater, 2017, 60: 1-24

14 Xia L, Wang S, Liu G, et al. Flexible $\mathrm{SnO}_{2} / \mathrm{N}$-doped carbon nanofiber films as integrated electrodes for lithium-ion batteries with superior rate capacity and long cycle life. Small, 2016, 12: 853-859

15 Lian P, Zhu X, Liang S, et al. High reversible capacity of $\mathrm{SnO}_{2} /$ graphene nanocomposite as an anode material for lithium-ion batteries. Electrochim Acta, 2011, 56: 4532-4539

16 Paek SM, Yoo EJ, Honma I. Enhanced cyclic performance and lithium storage capacity of $\mathrm{SnO}_{2}$ /graphene nanoporous electrodes 
with three-dimensionally delaminated flexible structure. Nano Lett, 2008, 9: 72-75

17 Reddy MV, Subba Rao GV, Chowdari BVR. Metal oxides and oxysalts as anode materials for Li ion batteries. Chem Rev, 2013, 113: 5364-5457

18 Wang Z, Wang Z, Madhavi S, et al. $\alpha-\mathrm{Fe}_{2} \mathrm{O}_{3}$-mediated growth and carbon nanocoating of ultrafine $\mathrm{SnO}_{2}$ nanorods as anode materials for Li-ion batteries. J Mater Chem, 2012, 22: 2526-2531

19 Zou Y, Wang Y. Sn@CNT nanostructures rooted in graphene with high and fast Li-storage capacities. ACS Nano, 2011, 5: 8108-8114

20 Wang D, Yang J, Li X, et al. Layer by layer assembly of sandwiched graphene/ $\mathrm{SnO}_{2}$ nanorod/carbon nanostructures with ultrahigh lithium ion storage properties. Energy Environ Sci, 2013, 6: 29002906

21 Shen L, Liu F, Chen G, et al. Encapsulation of $\mathrm{SnO}_{2}$ nanocrystals into hierarchically porous carbon by melt infiltration for highperformance lithium storage. J Mater Chem A, 2016, 4: 1870618710

$22 \mathrm{Hu}$ YY, Liu Z, Nam KW, et al. Origin of additional capacities in metal oxide lithium-ion battery electrodes. Nat Mater, 2013, 12: $1130-1136$

23 Kisu K, Iijima M, Iwama $\mathrm{E}$, et al. The origin of anomalous large reversible capacity for $\mathrm{SnO}_{2}$ conversion reaction. J Mater Chem A, 2014, 2: 13058-13068

24 Seng KH, Park M, Guo ZP, et al. Catalytic role of ge in highly reversible $\mathrm{GeO}_{2} / \mathrm{Ge} / \mathrm{C}$ nanocomposite anode material for lithium batteries. Nano Lett, 2013, 13: 1230-1236

25 Wang Y, Huang ZX, Shi Y, et al. Designed hybrid nanostructure with catalytic effect: beyond the theoretical capacity of $\mathrm{SnO}_{2}$ anode material for lithium ion batteries. Sci Rep, 2015, 5: 9164

26 Corma A, García H. Lewis acids as catalysts in oxidation reactions: from homogeneous to heterogeneous systems. Chem Rev, 2002, 102: $3837-3892$

27 Geng Z, Zhang C, Wang D, et al. Pore size effects of nanoporous carbons with ultra-high surface area on high-pressure hydrogen storage. J Energy Chem, 2015, 24: 1-8

28 Wang D, Geng Z, Li B, et al. High performance electrode materials for electric double-layer capacitors based on biomass-derived activated carbons. Electrochim Acta, 2015, 173: 377-384
29 Vinke P, van der Eijk M, Verbree M, et al. Modification of the surfaces of a gasactivated carbon and a chemically activated carbon with nitric acid, hypochlorite, and ammonia. Carbon, 1994, 32: 675-686

30 Geng Z, Xiao Q, Lv H, et al. One-step synthesis of microporous carbon monoliths derived from biomass with high nitrogen doping content for highly selective $\mathrm{CO}_{2}$ capture. Sci Rep, 2016, 6: 30049

31 Kimura R, Wakabayashi J, Elangovan SP, et al. Nepheline from $\mathrm{K}_{2} \mathrm{CO}_{3} /$ nanosized sodalite as a prospective candidate for diesel soot combustion. J Am Chem Soc, 2008, 130: 12844-12845

32 Kravchyk K, Protesescu L, Bodnarchuk MI, et al. Monodisperse and inorganically capped $\mathrm{Sn}$ and $\mathrm{Sn} / \mathrm{SnO}_{2}$ nanocrystals for highperformance Li-ion battery anodes. J Am Chem Soc, 2013, 135: 4199-4202

33 Luo L, Wu J, Luo J, et al. Dynamics of electrochemical lithiation/ delithiation of graphene-encapsulated silicon nanoparticles studied by in-situ TEM. Sci Rep, 2015, 4: 3863

34 Wang D, Li X, Wang J, et al. Defect-rich crystalline $\mathrm{SnO}_{2} \mathrm{im}$ mobilized on graphene nanosheets with enhanced cycle performance for Li ion batteries. J Phys Chem C, 2012, 116: 22149-22156

35 Hu R, Sun W, Liu H, et al. The fast filling of nano- $\mathrm{SnO}_{2}$ in CNTs by vacuum absorption: a new approach to realize cyclic durable anodes for lithium ion batteries. Nanoscale, 2013, 5: 11971-11979

Acknowledgements This work was supported by the National High Technology Research and Development Program of China (2012AA053305 and 2014AA052501) and the National Natural Science Foundation of China (21506224).

Author contributions Geng Z, Ji Y and Zhang C conceived the idea for the project. Geng $Z$ conducted material synthesis, structural characterizations and electrochemical test. Geng Z, Li B and Lv H discussed the results. Geng Z, Lv H and Xiao Q analyzed data. Geng Z, Ji Y and Zhang $\mathrm{C}$ drafted the manuscript. All authors discussed the manuscript.

Conflict of interest The authors declare no conflict of interest.

Supplementary information Supplementary material is available in the online version of this article. 


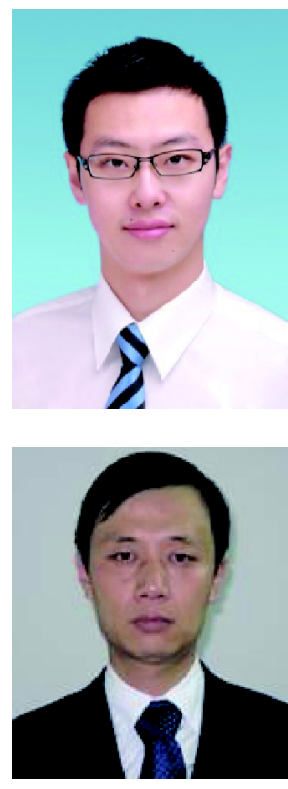

Zhen Geng obtained his PhD from Tongji University under the supervision of Prof. Cunman Zhang, in 2016. From 2014 to 2015, He worked as a visiting graduate student in the group of Prof. Yunfeng Lu, at the University of California, Los Angeles. Currently, he is working as a post-doctoral researcher at the Institute of Physics, Chinese Academy of Science (CAS), under the supervision of Prof. Hong Li. His research interest mainly focuses on nano-materials for energy storage, solid state electrolytes, lithium metal anode and solid state lithium batteries.

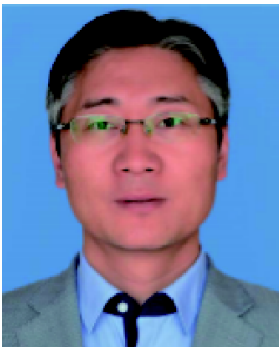

Yongjun Ji received his PhD degree from East China Normal University in 2012, under the supervision of Prof. Peng Wu. After postdoctoral research at Tsinghua University with Prof. Yadong Li, he joined the faculty of the Institute of Process Engineering, Chinese Academy of Sciences in 2014. He is currently an associate professor. His research interests include the synthesis and application of zeolite and nanomaterials.

Cunman Zhang is a professor in the School of Automotive Studies, Tongji University. His current research interests include the design and development of new energy storage systems for vehicles, the development and application of hydrogen infrastructure and energy storage materials.

\section{基于具有增强键能和电子吸引双功能特性的氧掺杂碳载体制备高性能二氧化锡/碳复合负极材料}

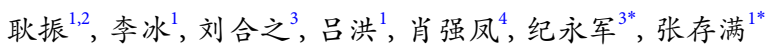

摘要 通过电化学活性材料与导电载体材料复合制备纳米复合材料, 对于高能量锂离子电池的发展至关重要. 本文利用水热法将含氧官 能团引入到纳米孔碳材料骨架上, 制备得到了骨架内均匀生长粒径为 $2-5 \mathrm{~nm}$ 的 $\mathrm{SnO}_{2}$ 纳米颗粒的纳米孔碳材料, 作为 $\mathrm{SnO}_{2} /$ 碳复合负极材 料其电化学性能显著提高. 与原始 $(\mathrm{CAC})$ 、氮掺杂碳( $\mathrm{NAC}$ )载体相比, 氧掺杂碳载体 $(\mathrm{OAC})$ 制备得到的 $\mathrm{SnO}_{2} /$ 碳复合材料表现出更优异的 电化学性能. $\mathrm{SnO}_{2} / \mathrm{OAC}$ 在 $500 \mathrm{~mA} \mathrm{~g}^{-1}$ 充放电速率下, 320 圈后其放电容量保持在 $1122 \mathrm{~mA} \mathrm{~h} \mathrm{~g}^{-1} ; 2000 \mathrm{~mA} \mathrm{~g}^{-1}$ 下其容量仍保持 $680 \mathrm{~mA} \mathrm{~h} \mathrm{~g}$. $\mathrm{SnO}_{2} / \mathrm{OAC}$ 优异的电化学性能主要归因于: 氧官能团作为Lewis酸, 可以在充电状态下从 $\mathrm{Sn}$ 纳米颗粒处吸引电子, 促进 $\mathrm{Sn}$ 向 $\mathrm{SnO}_{2}$ 的可逆转 化; 同时, 由于氧官能团的存在, $\mathrm{SnO}_{2}$ 纳米颗粒被有效地限制在了碳载体骨架内, 有效抑制了充放电过程中 $\mathrm{SnO}_{2}$ 纳米颗粒的团聚, 从而提高

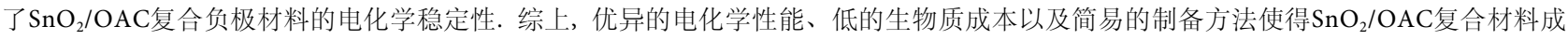
为一种非常有潜力的锂电池负极材料. 